\title{
M. J. Alexander, R. F. Spetzler, Pediatric Neurovascular Disease. Surgical, Endovascular, and Medical Management
}

\author{
Stuttgart, Thieme, New York, 2006, 224 pp, US \$149.95/ EUR 129.95
}

Nicolas de Tribolet

Published online: 5 February 2009

(C) Springer-Verlag 2009

This book is divided in three sections: I Medical and Diagnostic Evaluation and Issues, II Surgical Treatments, and III Endovascular Treatments.

The first section starts with an important chapter on the Development of the Cerebral Vasculature. This is well written and illustrated and helps to understand the pathogenesis of cerebral vascular malformations. The next chapter describes the congenital neurovascular syndromes in children such as Sturge-Weber, Hereditary Hemorrhagic Telangiectasia, Ehlers-Danlos, Pseudoxanthoma Elasticum and Progeria. The clinical characteristics of each syndrome are clearly presented. The third chapter of this section, Etiology and Management of Stroke in Children is particularly important and well documented with tables and illustrations. Finally, the chapter on Neuroangiography in children describes the technique and the possible complications.

The second section on surgical treatments includes chapters on Cavernous Malformations, Moyamoya Disease,

N. de Tribolet $(\triangle)$

Neurosurgery, HUG,

CH 1211 Geneva, Switzerland

e-mail: nicolas.detribolet@unige.ch cerebral aneurysms, Arteriovenous Fistulas, Spinal Vascular Malformations, and AVMs. Each technique is clearly described with excellent illustrations. The final chapter of this section addresses Radiosurgery. The third section on Endovascular Treatments includes chapters on Aneurysms, Arteriovenous Fistulas, AVMs, Vein of Galen Malformations (I found this chapter particularly interesting) and Spinal Vascular Malformations. Finally, there are chapters on Thrombolysis and Angioplasty. In each chapter there are "pearls" stressing particularly important aspects of the pathology or technique. Each chapter contains a wealth of references.

Colour illustrations are grouped in the middle of the volume. Although this is a textbook written by multiple authors, experts in their respective fields its presentation is remarkably homogeneous.

In the Preface, Michael Alexander insists on the importance of the multi-modal management of these malformations. One misses perhaps decision trees helping to chose and combine the various treatment modalities.

This book belongs to the library of neurosurgeons and interventional neuroradiologists both paediatric and adult. It should also be available to neuropaediatricians and paediatricians. 